EXTENDED REPORT

\title{
Occurrence and risk factors for falls in rheumatoid arthritis
}

\author{
C Armstrong, C M Swarbrick, S R Pye, T W O'Neill
}

Ann Rheum Dis 2005;64:1602-1604. doi: 10.1136/ard.2004.031195

See end of article for authors' affiliations

........................

Correspondence to: Dr Terence W O'Neill, ARC Epidemiology Unit, The University of

Manchester, Oxford Road, Manchester M13 9PT, UK; terence.o'neill@

manchester.ac.uk

Accepted 28 March 2005

Published Online First

7 April 2005

Objectives: To determine the one year period prevalence of falls by age and sex in patients with rheumatoid arthritis and the influence of concurrent medical treatment and disability on the occurrence of falls in this group.

Methods: A consecutive series of rheumatoid patients aged 35 years and over, attending hospital outpatient clinics at Hope hospital, Salford, were asked to complete an interview assisted questionnaire which asked about the occurrence and number of falls in the previous 12 months. Subjects who took part were asked about current treatment with antihypertensive agents, diuretics, sedatives or hypnotics, antidepressants, and a history of previous hip/knee surgery. They also completed the health assessment questionnaire (HAQ). Logistic regression was used to determine the association between these variables and falls in the previous 12 months.

Results: 253 men and women, mean age 62 years, were studied, and $84(33 \%)$ reported falling in the previous year ( $36 \%$ of women and $26 \%$ of men). Of these, $52 \%$ had fallen on more than one occasion. There was no important increase in the frequency of falls with age. After adjusting for age and sex, those who had fallen in the previous year were more likely to report taking antidepressant treatment (odds ratio $(O R)=2.09)$ and to have impairment in both walking $(O R=1.37)$ and rising $(O R=1.41)$. The HAQ score was higher in those who reported a fall than those who did not, though the difference was not statistically significant.

Conclusions: In this hospital based survey, one in three patients with rheumatoid arthritis reported falling in the previous 12 months. Falls were associated with self reported impairment in lower limb function.

R heumatoid arthritis is associated with an increased risk of osteoporotic fracture, including hip fracture. ${ }^{1-3}$ Osteoporotic fractures arise as a result of an interaction between increased bone fragility of which the major determinant is bone mass, and trauma, particularly falls. Data from many studies suggest that patients with rheumatoid arthritis have reduced bone mass compared to nonrheumatoid controls. $^{4-6}$ Rheumatoid patients might be considered to be at increased risk of falls for a variety of reasons, including the presence of lower limb joint involvement resulting in impaired mobility, balance, and postural stability; however, little is known about the occurrence of falls in rheumatoid arthritis.

Our aim in this study was to determine the one year period prevalence of falls by age and sex in patients with rheumatoid arthritis, and to determine the influence of concurrent medical treatment and disability on the occurrence of falls.

\section{METHODS \\ Subjects}

Men and women with rheumatoid arthritis aged 35 years and over attending hospital outpatient clinics at Hope hospital, Salford-either for clinical review or for blood monitoring for anti-rheumatic treatment-were invited to complete an interviewer assisted questionnaire concerning falls. Subjects were asked about the occurrence of falls: "Have you fallen in the last 12 months?" and, if yes, "How many times?". We did not include a formal definition of falls, though falls caused by road accidents and violence were excluded.

Subjects were asked also about the duration of rheumatoid arthritis, previous knee or hip surgery (any), and whether they were currently taking treatment that might influence their risk of falls (antidepressants/sedatives hypnotics/anti-

hypertensives/diuretics). They were asked also to complete the health assessment questionnaire (HAQ). ${ }^{7}$ Ethical approval for the study was obtained from the Salford and Trafford ethics committee.

\section{Statistical analysis}

The proportions of patients who reported a fall in the previous year and who reported more than one fall (multiple falls) in the previous year were calculated by sex and by 10 year age group. Logistic regression was used to explore risk factors associated with falls, with falls in the last year as the dependent variable, and the results were expressed as odds ratios (OR) and 95\% confidence intervals (CI). The analysis was repeated using multiple falls as the dependent variable. Statistical analysis was undertaken using STATA. ${ }^{8}$

\section{RESULTS}

\section{Subjects}

We interviewed 253 patients: 72 men, mean age 61.1 years, and 181 women, mean age 62.3 years. The mean duration of disease was 13.4 years; $17.8 \%$ reported having had previous hip or knee surgery, $32.8 \%$ were taking concurrent antihypertensive drug treatment, $8.3 \%$ were taking sedative/ hypnotics, $17.4 \%$ were taking diuretics, and $15.4 \%$ were taking antidepressants (table 1).

\section{Prevalence of falls}

Eighty four subjects (33\%) reported falls in the previous 12 months. Of these, $44(52 \%)$ fell on more than one occasion. Falls were more common in women than in men $36 \% v$ $26 \%)$, though the difference was not statistically significant. Table 2 gives the proportion of patients who fell in the

Abbreviations: $H A Q$, health assessment questionnaire 


\begin{tabular}{|ll|}
\hline \multicolumn{2}{l|}{ Table 1 Subject characteristics } \\
\hline Variable & \\
\hline Age (years) & \\
Duration of RA (years)* & $62.0(11.2)$ \\
HAQ score* & $13.4(10.2)$ \\
Hip/knee surgery & $1.86(0.78)$ \\
Drug treatment & $45(17.8 \%)$ \\
Antihypertensives & $83(32.8 \%)$ \\
Diuretics & $44(17.4 \%)$ \\
Sedatives/hypnotics & $21(8.3 \%)$ \\
Antidepressants & $39(15.4 \%)$ \\
\hline Values are *mean (SD), or $\mathrm{n}(\%)$. \\
HAQ, health assessment questionnaire; RA, rheumatoid \\
arthritis. \\
\hline
\end{tabular}

previous 12 months, and the proportion who fell on more than one occasion, by sex and age group. There was no significant trend towards an increased risk of falls (any or multiple) with age in either men or women. Of the 84 patients who reported a fall, four sustained a fracture (wrist, vertebra, nose, rib).

\section{Risk factors for falls}

After adjusting for age and sex, those who fell in the previous 12 months were more likely to report taking antidepressant therapy $(\mathrm{OR}=2.09)$ than those who did not fall (table 3$)$. Diuretic therapy $(\mathrm{OR}=1.79)$ and sedative therapy $(\mathrm{OR}=1.96)$ were also associated with an increased risk of falling, though the confidence intervals embraced unity. An increasing number of treatments taken by an individual (range 0 to 4 ) was associated with a significantly increased risk of falling $(\mathrm{OR}=1.44)$. Previous hip/knee surgery was associated with an increased risk of falling $(\mathrm{OR}=1.84)$, though the confidence intervals embraced unity. Duration of rheumatoid arthritis did not appear to influence the susceptibility to falls.

The mean HAQ score was 1.98 in fallers and 1.79 in nonfallers, though the difference was not statistically significant. In terms of the individual HAQ domains, increased difficulty in walking $(\mathrm{OR}=1.37 ; 95 \% \mathrm{CI} 1.02$ to 1.84$)$ and in rising $(\mathrm{OR}=1.41 ; 95 \%$ CI 1.06 to 1.89$)$ were associated with an increased risk of falls (table 4). Repeating these analyses using multiple falls ( $v$ single or no falls) as the dependent variable did not influence the results (data not shown).

\section{DISCUSSION}

In this study, one in three patients with rheumatoid arthritis aged 35 years and over reported falling during the previous year. Impaired walking and rising and concurrent antidepressant treatment were associated with an increased risk of falls in this patient group.

There are several methodological issues that need to be considered in interpreting the results. Data concerning falls were based on self report over the previous 12 month period, and poor recall (forgetting falls) may have resulted in an
Table 3 Risk factors for falls: age, sex, previous knee/hip surgery, and drug treatment

\begin{tabular}{ll}
\hline Risk factor & OR $(95 \% \mathrm{Cl})^{*}$ \\
\hline Age (years) & Referent \\
35 to 45 & $1.18(0.38$ to 3.66$)$ \\
45 to 55 & $0.85(0.28$ to 2.57$)$ \\
55 to 65 & $0.91(0.30$ to 2.75$)$ \\
65 to 75 & $0.89(0.26$ to 3.07$)$ \\
$75+$ & $1.58(0.86$ to 2.89$)$ \\
Sex (F $v$ M) & $1.84(0.95$ to 3.57$)$ \\
Previous hip/knee surgery $\dagger$ & $1.00(0.56$ to 1.79$)$ \\
Antihypertensive agents $\dagger$ & $1.79(0.90$ to 3.58$)$ \\
Diuretics $\dagger$ & $1.96(0.79$ to 4.85$)$ \\
Sedatives $\dagger$ & $2.09(1.04$ to 4.20$)$ \\
Antidepressants $\dagger$ & $1.44(1.04$ to 1.99$)$ \\
Number of drugs (0 to 4) & \\
\hline
\end{tabular}

*Adjusted for age and sex.

†Yes $v$ No/Don't know.

$\mathrm{Cl}$, confidence interval; $\mathrm{OR}$, odds ratio.

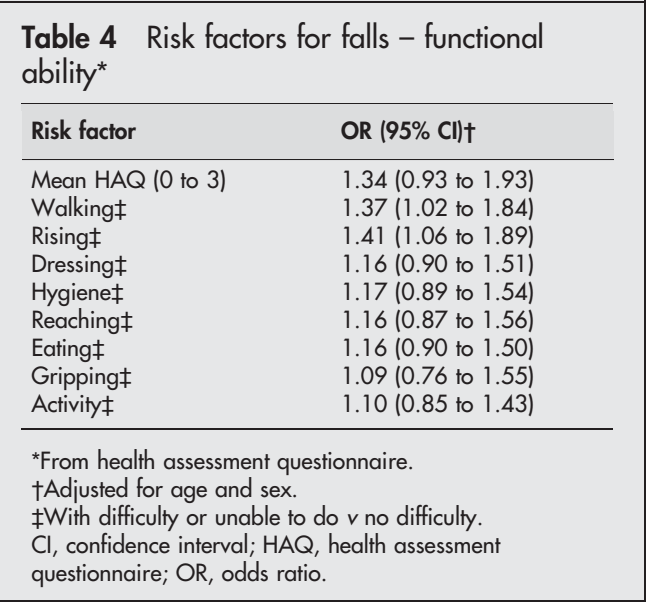

underestimation of the true occurrence of falls. In a previous study of ambulatory men and women aged 60 years and over, $13 \%$ of subjects who reported a fall during weekly reporting did not report having experienced a fall at the end of a 12 month period. ${ }^{9}$ Some caution is therefore required in interpreting the prevalence data. The effect of any misclassification owing to poor recall would be, however, to tend to reduce the chance of finding significant biological associations.

We studied rheumatoid patients attending a hospital outpatient department. Such cases are likely to be more severe than those managed in the primary care sector and our results should not be extrapolated outside this setting. Information about risk factors for falls, including functional impairment, was obtained by self report using questionnaires and was therefore subject to errors of recall. Objective

Table 2 Prevalence of falls by sex and age group

\begin{tabular}{|c|c|c|c|c|c|c|c|c|c|}
\hline \multirow[b]{2}{*}{ Age (years) } & \multicolumn{3}{|c|}{ Women } & \multicolumn{3}{|c|}{ Men } & \multicolumn{3}{|c|}{ Both } \\
\hline & $\mathbf{n}$ & $\begin{array}{l}\text { Any fall } \\
\text { (n }(\%) \text { ) }\end{array}$ & $\begin{array}{l}>1 \text { fall } \\
\text { (n (\%)) }\end{array}$ & n & $\begin{array}{l}\text { Any fall } \\
\text { (n }(\%))\end{array}$ & $\begin{array}{l}>1 \text { fall } \\
\text { (n (\%)) }\end{array}$ & $n$ & $\begin{array}{l}\text { Any fall } \\
\text { (n }(\%))\end{array}$ & $\begin{array}{l}>1 \text { fall } \\
\text { (n }(\%) \text { ) }\end{array}$ \\
\hline 35 to 44 & 11 & $4(36.4)$ & $3(27.3)$ & 7 & $2(28.6)$ & $1(14.3)$ & 18 & $6(33.3)$ & $4(22.2)$ \\
\hline 45 to 54 & 36 & $16(44.4)$ & $9(25.0)$ & 17 & $4(23.5)$ & $2(11.6)$ & 53 & $20(37.7)$ & $11(20.8)$ \\
\hline 55 to 64 & 57 & 19 (33.3) & $13(22.8)$ & 20 & $5(25.0)$ & 3 (15.0) & 77 & $24(31.2)$ & $16(20.8)$ \\
\hline 65 to 74 & 56 & $20(35.7)$ & $6(10.7)$ & 17 & $4(23.5)$ & $1(5.9)$ & 73 & $24(32.9)$ & $7(9.6)$ \\
\hline $75+$ & 21 & $6(28.6)$ & $5(23.8)$ & 11 & $4(36.4)$ & $1(9.1)$ & 32 & $10(31.3)$ & $6(18.8)$ \\
\hline
\end{tabular}


measurements would have provided a more accurate indication of functional status. Finally our study was cross sectional and it was not therefore possible to determine the temporal nature of any observed associations-it is possible, for example, that the occurrence of a fall may result in impaired walking and rising rather than the latter predisposing to falls. Prospective studies are required to confirm our findings and also to characterise the temporal nature of the observed associations.

As in most previous studies of non-rheumatoid subjects, falls were more common in women than in men. ${ }^{10-12}$ In contrast, however, we found no important increase in the risk of falls with age in our sample. ${ }^{11}{ }^{14}$ The reason for this is unclear.

We did not include a control group of non-rheumatoid subjects and cannot therefore comment directly on whether rheumatoid arthritis per se is linked with an increased risk of falls. In a previous population based survey, however, undertaken in the early 1990s in the United Kingdom and using the same questionnaire as was used here, the frequency of falls among women aged 50 to 79 years was $26 \% .^{15}$ This compares with a frequency of $36 \%$ in our rheumatoid patient group at this age, suggesting that those with rheumatoid arthritis may have an increased susceptibility to falling; however, caution is needed in interpreting the data because of methodological differences (design/setting) between the studies. There are few other comparative data, though in a prospective study of 570 rheumatoid patients in California, mean age 64.9 years, the one year prevalence of falls (31\%) was similar to ours. ${ }^{16}$

Previous studies have identified arthritis as a risk factor for falls in the majority of studies, though not all. ${ }^{12}{ }^{17-19}$ In most studies, however, the nature of the underlying arthritis was not specified. In a prospective study of elderly women, those with self reported osteoarthritis were more likely to fall than those without. ${ }^{20}$ An increased risk of falling was also observed in those with hip pain. ${ }^{21}$ In a prospective study of rheumatoid patients with evidence of functional limitation the risk of falls was increased by a factor of just over twofold compared with a group of controls without functional limitation. ${ }^{22}$ Despite the relative lack of data concerning occurrence of falls in rheumatoid arthritis, there is evidence that falls are an important concern for patients, with up to $50 \%$ reporting fear of falling and just under $40 \%$ reporting modified activities owing to fear of falls. ${ }^{16}$

Our finding of an association between impaired walking and rising and falls is consistent with impaired lower limb function as a risk factor for falls in rheumatoid arthritis. This is in keeping with studies in non-rheumatoid patients. ${ }^{10} 23$ Similarly previous studies in non-rheumatoid subjects have suggested that various drugs, including antidepressants, sedatives, and diuretics, have been associated with an increased risk of falls, with the risk increasing with increasing numbers of drugs. ${ }^{17}{ }^{24-26}$ Our results are consistent with these findings, though perhaps because of relatively small numbers some of the associations did not attain conventional levels of statistical significance.

Cross sectional and prospective studies suggest that patients with rheumatoid arthritis have lower bone mass than non-rheumatoid controls and are therefore at increased risk of fracture..$^{4-6}$ Our data highlight the relatively high frequency of falls in rheumatoid arthritis. Measures to prevent fractures in this patient group should therefore focus not just on pharmacological treatment to prevent bone loss but also on measures to prevent falls.

In conclusion, falls in rheumatoid patients are common, with one in three reporting a fall in the previous year.
Measures to prevent falls in this group should be considered, particularly among those who are at increased risk of fracture.

\section{ACKNOWLEDGEMENTS}

We would like to thank the Arthritis Research Campaign for their support.

\section{Authors' affiliations}

C Armstrong, Department of Rheumatology, Hope Hospital, Salford, UK C M Swarbrick, S R Pye, T W O'Neill, ARC Epidemiology Unit, The University of Manchester, Manchester, UK

\section{REFERENCES}

1 Hooyman JR, Melton $\sqcup$, Nelson AM, O'Fallon WM, Riggs BL. Fractures after rheumatoid arthritis: a population-based study. Arthritis Rheum 1984;27:1353-61.

2 Cooper C, Coupland C, Mitchell M. Rheumatoid arthritis, corticosteroid therapy and hip fracture. Ann Rheum Dis 1995;54:49-52.

3 Huusko TM, Korpela M, Karppi P, Avikainen V, Kautiainen H, Sulkava R. Threefold increased risk of hip fractures with rheumatoid arthritis in central Finland. Ann Rheum Dis 2001;60:521-2.

4 Deodhar AA, Woolf AD. Bone mass measurement and bone metabolism in rheumatoid arthritis. A review. Br J Rheumatol 1996;35:309-22.

5 Haugeberg G, Uhlig T, Falch JA, Halse Jl, Kvein TK. Bone mineral density and frequency of osteoporosis in female patients with rheumatoid arthritis. Arthritis Rheum 2000;43:522-30.

6 Kroot EJ, Laan RF. Bone mass in rheumatoid arthritis. Clin Exp Rheumatol 2000;18(suppl 21):S12-15.

7 Fries JF, Spitz P, Kraines RG, Holman HR. Measurement of patient outcomes in arthritis. Arthritis Rheum 1980;23:137-45.

8 StataCorp. STATA statistical software: release 6.0. College Station, Texas: Stata Corporation, 1999.

9 Cummings SR, Nevitt MC, Kidd S. Forgetting falls. The limited accuracy of recall of falls in the elderly. J Am Geriatr Soc 1988;36:613-16.

10 Tinetti ME, Speechley M, Ginter SF. Risk factors for falls among elderly persons living in the community. N Engl J Med 1988;319:1701-7.

11 Wickham C, Cooper C, Margetts BM, Barker DJ. Muscle strength, activity,

12 O'Loughlin JL, Robitaille Y, Boivin JF, Suissa S. Incidence of and risk factors for falls and injurious falls among the community-dwelling elderly. Am J Epidemiol 1993;137:342-54.

13 Blake AJ, Morgan K, Bendall MJ, Dallosso H, Ebrahim SB, Arie TH, et al. Falls by elderly people at home: prevalence and associated risk factors. Age Ageing 1988;17:365-72.

14 Campbell AJ, Borrie MJ, Spears GF, Jackson SL, Brown JS, Fitzgerald JL. Circumstances and consequences of falls experienced by a community population 70 years and over during a prospective study. Age Ageing 1990;19:136-41.

15 O'Neill TW, Varlow J, Reeve J, Reid DM, Todd C, Woolf AD, et al. Fall frequency and incidence of distal forearm fracture in the UK. J Epidemiol Community Health 1995;49:597-8.

16 Fessel KD, Nevitt MC. Correlates of fear of falling and activity limitation among persons with rheumatoid arthritis. Arthritis Care Res 1997; 10:222-8.

17 Campbell AJ, Borrie MJ, Spears GF. Risk factors for falls in a communitybased prospective study of people 70 years and older. J Gerontol 1989;44:M1 12-17.

18 Northridge ME, Nevitt MC, Kelsey JL. Non-syncopal falls in the elderly in relation to home environments. Osteoporosis Int 1996;6:249-55.

19 Schwartz AV, Villa ML, Prill M, Kelsey JA, Galinus JA, Delay RR, et al. Falls in older Mexican-American women. J Am Geriatr Soc 1999;47:1371-8.

20 Arden NK, Nevitt MC, Lane NE, Gore LR, Hochberg MC, Scott JC, et al. Osteoarthritis and risk of falls, rates of bone loss, and osteoporotic fractures. Arthritis Rheum 1999;42:1378-85.

21 Nahit ES, Silman AJ, Macfarlane GJ. The occurrence of falls among patients with a new episode of hip pain. Ann Rheum Dis 1998;57:166-8.

22 Fessel K, Yelin E, Henke C, Nevitt M. Prevalence, predictors and consequences of falls in RA patients. Arthritis Rheum 1992;35:S83.

23 Sorock GS, Labiner DM. Peripheral neuromuscular dysfunction and falls in an elderly cohort. Am J Epidemiol 1992;136:584-91.

24 Myers AH, Baker SP, van Natta ML, Abbey H, Robinson EG. Risk factors associated with falls and injuries among elderly institutionalised persons. Am J Epidemiol 1991;133:1179-90.

25 Cumming RG, Miller JP, Kelsey JL, Davis P, Arfken CL, Birge SJ, et al. Medications and multiple falls in elderly people: the St Louis OASIS study. Age Ageing 1991;20:455-61.

26 Leipzig RM, Cumming RG, Tinetti ME. Drugs and falls in older people: a systematic review and meta-analysis. I. Psychotropic drugs. J Am Geriatr Soc
1999;47:30-9. 